\title{
Review on Diagnostic Methods of Trypanasomosis
}

\author{
Muluneh Hailu*, Getahun Endale and Lema Gemeda \\ Department of Biotechnology, School of Engineering and Technology, Sharda University, India
}

Submission: April 10, 2019; Published: April 23, 2019

*Corresponding author: Muluneh Hailu, Department of Biotechnology, School of Engineering and Technology, Sharda University, Greater Noida UP, India

Abstract

Trypanosomosis caused by genus Trypanosoma transmitted through bites by different species of Glossina and mechanically by a number of biting flies such as Tabanus and Stomoxys spp. genus Trypanosoma is an important livestock disease causing significant losses in cattle. Trypanosomosis is the most devastating disease, which leads to a slow progressive loss of body condition accompanied by anemia, weakness, collapse and death. The specific clinical diagnosis of trypanosomosis is difficult due to non-specific clinical signs coupled with intermittent fever and low parasitemia's. The most common diagnostic method are parasitological, serological and molecular diagnostic methods. Parasitological detection techniques are highly specific, but their sensitivity is relatively low. Serodiagnosis of diseases depends mainly on antigen-antibody reaction in the blood serum. The most important one is Complement fixation test, the card agglutination trypanosomosis test (CATT), indirect fluorescent antibody test (IFAT) and Enzyme linked immunosorbent assay (ELISA). Polymerase chain reaction (PCR) has been used to amplify trypanosome DNA from genetic material isolated from both blood and buffy coat preparations. The sensitive and specific diagnosis and their applicability in the field are prerequisites for the epidemiological surveys. In fact, the accuracy of the work will be authenticated if two or more methods that complement each other are used.

Keywords: Cattle; Trypanosomosis; Diagnosis; PCR

Abbreviations: IFAT: Indirect Fluorescent Antibody Test; ELISA: Enzyme linked immunosorbent assay; PCR: Polymerase Chain Reaction; CATT: Card Agglutination Trypanosomosis Test; BCT: Buffy Coat Approach; HCT: Haematocrit Centrifugation Technique; PCV: Packed Cell Volume; CFT: Complement Fixation Test

\section{Introduction}

Trypanosomosis, an important protozoan disease caused by the genus Trypanosoma transmitted through bites by different species of Glossina and mechanically by a number of biting flies such as Tabanus and Stomoxys spp. It is a serious disease in domestic livestock that causes a significant negative impact in food production and economic growth of many parts of the world, particularly in Sub-Saharan Africa [1]. African bovine trypanosomosis is a collective term for a group of diseases brought about by one or more of the pathogenic trypanosome species namely: T. vivax, T. congolense and T. brucei. It is a wasting disease in which there is a slow progressive loss of condition accompanied by increasing anemia and weakness to the point of extreme emaciation, collapse and death [2].

Diagnosis is an essential element in the management of disease, both at the level of individual patient care and at the level of disease-control in populations. Diagnostic tests should be simple, rapid, specific and highly sensitive. They also should ideally differentiate between closely related parasites, especially if the disease syndromes they cause require different management approaches. They should be suitable for field application and the cost for these tests should be within the means of the communities affected by the disease [3].
The most common diagnostic method are parasitological, serological and molecular diagnostic methods. parasitological detection techniques are highly specific, but their sensitivity is relatively low. Serodiagnosis of diseases depends mainly on antigen-antibody reaction in the blood serum. The most important one is Complement fixation test, the card agglutination trypanosomosis test (CATT), indirect fluorescent antibody test (IFAT) and Enzyme linked immunosorbent assay (ELISA). Polymerase chain reaction (PCR) has been used to amplify trypanosome DNA from genetic material isolated from both blood and buffy coat preparations. Rapid, efficient and reproducible procedures for isolating DNA before PCR amplification are essential for confirmation of infection [4]. Hence, the major objective of this review is to determine the major diagnostic methods of trypanosomes.

\section{Diagnostic Methods of Trypanasomosis}

\section{Parasitological diagnosis}

The exam of wet blood movies and Giemsa-stained thick and skinny constant blood movies with the useful resource of a light microscope had been used as diagnostic techniques ever in view that they had been first used to become aware of the etiological agents of trypanosomosis. With a wet smear, a drop of blood may 
be examined subsequent to the animal, supplied that a microscope is available. Thin and thick blood smears constant in methanol or acetone and stained with Giemsa can be used inside the laboratory to hit upon blood parasites and determine trypanosome species concerned, respectively. but those techniques aren't sensitive sufficient to detect low parasite ranges, feature of the ailment in huge animals [5].

Parasite concentration techniques including the haematocrit centrifugation approach (HCT) defined via Woo [6] and its progressed model, the buffy coat approach (BCT) defined by Murray [7] had been developed to enhance the detection capacity of parasitological method. The Parasite concentration techniques such as the haematocrit centrifugation technique (HCT) described by Woo [6] and its improved version, the buffy coat technique (BCT) described by Murray [7] were developed to improve the detection capacity of parasitological technique. The two methods are associated with increased diagnostic sensitivity following concentration of parasites in the buffy coat after centrifugation. The packed cell volume (PCV \%) can be determined simultaneously as a measure of anemia. With the BCT, the three most important trypanosome species in ruminants can be identified by their characteristic movement patterns, with a possibility for estimation of parasitemia through a scoring system [8]. The analytical sensitivity of BCT depends on the species of trypanosome as has been demonstrated by Paris [8], with the smallest numbers detectable per milliliter of blood being $2.5 \times 102,5 \times 102$ and $5 \times 103$, for T. congolense, T. vivax and T. brucei, respectively. On the other hand, HCT is the most sensitive microscopic technique to detect T. brucei in bovine blood. Strategies are related to accelerate diagnostic sensitivity following awareness of parasites in the buffy coat after centrifugation. The packed cell extent (PCV \%) can be determined concurrently as a measure of anemia. With the BCT, the three maximum vital trypanosome species in ruminants can be identified by their characteristic motion styles, with a possibility for estimation of parasitaemia thru a scoring machine [8]. The analytical sensitivity of BCT relies upon on the species of trypanosome as has been demonstrated by Paris [8], with the smallest numbers detectable according to milliliter of blood being $2.5 \times 102,5 \times 102$ and $5 \times 103$, for T. congolense, T. vivax and T. brucei, respectively. then again, HCT is the maximum touchy microscopic approach to hit upon T. brucei in bovine blood.

Animal inoculation has evolved as an alternative parasitological technique which involves the transfer of trypanosomes from a suspected case to another vertebrate or invertebrate host. This method has the advantage to preserve (stability) remoted trypanosomes for further investigations [5]. Laboratory rodents are inoculated with zero.2-0. Five $\mathrm{ml}$ (depending on size of rodent) of freshly amassed trypanosome-tremendous blood. alternatively, only $50 \%$ of T. congolense can be conserved in mice. Trypanosoma vivax rarely establishes in mice, and, if it does, the ensuing parasitaemia is pretty brief [9].

Other much less typically employed parasite detection strategies are xenodiagnoses, the feeding of a smooth susceptible vector species on a suspected case of trypanosomosis, after which it is both dissected and examined for trypanosomes or allowed to feed on a smooth animal which is itself tested for the improvement of contamination [5] and the usage of in vitro tradition method for the detection of trypanosomes thru inoculation of lifestyle medium with blood however with low achievement rate [10].

Microscopical examination of wet or Geimsa stained thin and thick blood films is considered the traditional method for trypanosome diagnosis in the field. Although being widely used, these techniques are not considered sensitive enough to detect the low parasite levels especially in chronic cases. Therefore, these methods have been modified using concentration techniques to improve the sensitivity of the microscopic based methods [11]. Parasite detection techniques are highly specific, but their sensitivity is relatively low. Due to this low sensitivity, the apparent parasitological prevalence of trypanosomosis is generally lower than the true parasitological prevalence. Moreover, in areas where trypanocide drugs are used extensively, parasites may not be detected [8]. The most commonly used concentration method is the haematocrit centrifugation technique (HCT) developed by Woo [6] using centrifugation of microhematocrit capillary tubes containing the blood sample and examination of the buffy coat/ plasma junction under the microscope. In a positive diagnosis, trypanosomes are found wriggling at the junction of the buffy layer and the plasma [12].

Wet blood film: These are made by placing a drop of blood on a microscope slide and covering with a cover-slip. The blood is examined microscopically using an $\mathrm{x} 40$ objective lens. Approximately 50-100 fields are examined. Trypanosomes can be recognized by their movement among the RBC. The method is simple, inexpensive and gives immediate results. Depending on the trypanosome size and movements a presumptive diagnosis can be made of the trypanosome species [12].

Thick blood smear technique: The method is simple and relatively inexpensive, but results are delayed because of the staining process. Trypanosomes are easily recognized by their general morphology but may be damaged during the staining process. This may make it difficult to identify the species [13].

Thin blood smear technique: Usually, both a thin and thick smear is made from the same sample. Thick smears contain more blood than thin smears and, hence, have a higher diagnostic sensitivity. While, thin smears allow trypanosome species identification.

\section{Serological diagnosis}

Serodiagnosis of diseases depends mainly on antigen-antibody reaction in the blood serum. The essential element in immunodiagnostic is the availability of species-specific test antigens and/or highly specific antibodies. Because parasites contain thousands of potentially antigenic polypeptides, glycoproteins and glycolipids, many of which are shared with unrelated species and even with bacteria, there has been great difficulty in developing sufficiently specific immunodiagnostic tests [3]. The advantage of 
using a robust serological test is that they can be used for mass screening without the need for expensive analytical equipment's. However, the main drawback of serological tests is the inability of these tests to differentiate current from previous infection since antibodies frequently persist far longer than the infectious agent within the host.

Complement fixation test (CFT): Complement fixation test is one of the widely used immunodiagnostic tests for the detection of antibodies or antigens for a variety of blood borne parasites. Complement is a biological substance present in the sera of normal humans and animals helping in the clearance of invading pathogens [14]. CFT uses sheep red blood cells (RBC) as an indicator system, meaning that in a positive test, the complement is bound to the antigen-antibody complex and is not free to interact with sheep RBC which in turn settle to the bottom of the well forming a button shape. Alternatively, in a negative reaction, the complement remains free due to the absence of antigen-antibody reaction and react with the sheep RBC leading to lyses and the serum color turns pink [14], as shown in Figure below. This test is considered the official diagnostic test for infectious diseases such as babesiosis, brucellosis and piroplasmosis due to ease of application and suitability for in field screening $[15,16]$. However, the main drawback of this test is the lack of sensitivity especially during the late stages of disease and the difficulty encountered during the preparation of reagents.

Card agglutination trypanosomosis test: The card agglutination trypanosomosis test (CATT) has been widely used for in field diagnosis of infections with T. b. gambiense because it is considered a rapid, cheap and practical serological test $[17,18]$. The antigens originate from particular variable antigen types (VATs) of T. $b$. gambiense that are highly conserved across the range of this species and they are expressed early with infection. Therefore, the majority of infected individuals develop antibodies that cause visible agglutination when whole blood or serum is mixed with the antigen on the card $[5,11,18]$. The sensitivity of the test for T. b. gambiense varies between $87 \%$ and $98 \%$, with an average of $95 \%$ [19].

Indirect fluorescent antibody test (IFAT): In this test, blood films from infected laboratory animals are fixed and used as a source of infectious agent antigens to which antibodies in test sera may bind specifically. Bound antibodies are visualized using anti-host species immunoglobulin conjugated to a fluorescent dye using a fluorescent microscope [9]. An example of using IFAT in the screening of blood borne parasitic infections was the diagnosis of Theileria equi and Babesia caballi in domestic horses, southwest Mongolia [20]. The test was able to detect $78.8 \%$ and $65.7 \%$ of the examined animals to be infected with the two parasites, respectively.

Enzyme linked immunosorbent assay (ELISA): Another important widely used immunodiagnostic test for the detection of antibodies or antigens of blood borne parasites diagnosis is ELISA; developed in 1971 by Engvall and Perlman for the measure- ments of antibodies for the diagnosis of different diseases.Two types of ELISA have been developed depending on the target to be detected, the indirect ELISA is used for the detection of antibodies in a serum sample, based on the adhesion of a known antigen to the surface of a 96-well microtiter plate followed by the addition of the patient serum sample from which the antibodies will bind to the antigens if prior exposure has taken place. Finally, second antibodies labelled with an enzyme that catalyze the conversion of a colorless substrate to a visible colored product are added [21]. The other type is the direct ELISA such as antigen-ELISA or the double sandwich ELISA; used for antigen detection in which specific antibodies adhere to the surface of the microtiter plate. The sample to be examined is then applied and any antigen present is bound by the antibodies. Finally, the labelled antibodies with the enzyme are attached [21].

\section{Molecular Diagnosis}

Molecular diagnostic testing is now firmly established as a routine diagnostic tool for infectious diseases. However, molecular tests have broader applications including use in epidemiological investigations, therapeutic strategies decisions and predicting the development of diseases.

polymerase chain reaction (PCR): Several studies have shown that PCR is a specific and more sensitive method in the diagnosis of trypanosomosis in experimental as well as natural infections [22-27]. In actual fact, two periods of the trypanosome infection process must be distinguished; early in an infection, parasitological and PCR techniques show a very similar sensitivity (80\%), but during the chronic phase of infection, parasitological examination exhibits a very low sensitivity and PCR is much more sensitive than the parasitological methods in such situation [22]. In the Sideradougou area of Burkina Faso, an epidemiological survey carried out in 1000 herds of cattle indicated a parasitological prevalence of 5.3\%; a representative sub-sampling of 260 samples tested with PCR indicated a prevalence of $11.5 \%$ [28]. In another study, carried out in 76 goats in The Gambia, the parasitological prevalence was $8 \%$ against $24 \%$ with PCR [29]. In such studies, the rate of positive samples by PCR is generally two to three times higher than that by the buffy coat method $[27,28]$. The detection and identification of trypanosomes by molecular means should as a principle always be based upon stable, parasite-specific genetic characteristics [5]. Currently a more sensitive and species-specific molecular techniques such as ITS1 PCR and PCR-RFLP are available to aid the accurate diagnosis of trypanosomosis and undertake drug efficacy studies in animals [30].

Polymerase chain reaction (PCR) has been used to amplify trypanosome DNA from genetic material isolated from both blood and buffy coat preparations. Rapid, efficient and reproducible procedures for isolating DNA before PCR amplification are essential for confirmation of infection [4]. However, the protocols to extract the DNA from samples are expensive, require specific instruments and kits and are time consuming. The transport of the collected fresh samples including blood, body fluids and tissues from animals and humans from the collection point to the laboratory may 
involve leakage risks because these samples are considered a potential biohazard to humans, animals or the environment. This is because they contain biological organisms such as viruses, bacteria, fungi and parasites and their toxins [31]. Moreover, the transport of the samples may involve degradation of the genomic material due to temperature variation [32]. In recent years, PCR has been developed and became widely used for the detection of trypanosomes. This approach has overcome the constraints of parasitological and serological techniques $[33,34]$. PCR has proven to be highly sensitive and specific for trypanosome detection [35]. The use of PCR in detecting the trypanosome DNA is reported to be the most reliable and accurate technique to assess and follow up the efficacy of trypanosomosis treatment [36,37].

\section{Conclusion}

Cattle trypanosomosis is the most important diseases causing the economic losses particularly in the Cattle rearing areas. Still it is the most ignorant animal in the most part of the world and now it is very important to focus on the control strategies and launch the most effective campaign to control the most devastating disease of the camel. In majority of the cases the diagnoses only based on the unreliable clinical signs and control the disease by treating the animal on these clinical signs. The Parasitological examination of wet or Geimsa stained thin and thick blood films is considered the traditional method for trypanosome diagnosis in the field. In a study to compare the use of Ag-ELISA and PCR in detecting trypanosomes in experimentally infected flies, Ouma showed that Ag- ELISA and PCR detected $71.4 \%$ and $96 \%$ of T. congolense and $98.4 \%$ and $97.6 \%$ of $T$. brucei s.l. infections, respectively, indicating a high sensitivity of detecting trypanosomes using PCR. Its miles concluded that practitioners need to recognition at the correct prognosis and the use of the most reliable and touchy technique. Therefore, PCR has proven to be highly sensitive and specific for trypanosome detection [35].

\section{References}

1. Griffiths M (2010) Improving the safety and quality of milk: Improving quality in milk products. (Edition 1), Woodhead Publishing, Sawston, Cambridge, UK, pp. 520.

2. Harley KG, Huen K, Aguilar Schall R, Holland NT, Bradman A, et al (2011) Association of organophosphate pesticide exposure and paraoxonase with birth outcome in Mexican-American women. Plosone 6(8): e23923.

3. Shaker EM, Elsharkawy EE (2015) Organochlorine and organophosphorus pesticide residues in raw buffalo milk from agro-industrial areas in Assiut, Egypt. Environ Toxicol Pharmacol 39(1): 433-440.

4. Zhou S, Tang Q, Jin M, Liu W, Niu L, et al. (2014) Residues and chiral signatures of organochlorine pesticides in mollusks from the coastal regions of the Yangtze River Delta: Source and health risk implication. Chemosphere 114: 40-50.

5. Rengasamy P, Kantharimuthu A, Balaraman M, Sivanesan S (2016) Development of ELISA kit for the assay of dichlorodiphenyltrichloroethane in milk and milk products. Afr J Food Sci 10(3): 41-47.

6. Fagnani R, Beloti V, Battaglini A, Dunga K, Tamanini R (2011) Organophosphorus and carbamates residues in milk and feedstuff supplied to dairy cattle. Pesq Vet Bras 31(7): 598-602.
7. Melgar M, Santaeufemia M, Garcia MA (2010) Organophosphorus pesticide residues in raw milk and infant formulas from Spanish northwest. J Environ Sci Health B 45(7): 595-600.

8. Salas J, González M, Noa M, Pérez N, Díaz G, et al. (2003) Organophosphorus pesticide residues in Mexican commercial pasteurized milk. J Agric Food Chem 51(15): 4468-4471.

9. Aytenfsu S, Mamo G, Kebede B (2016) Review on chemical residues in milk and their public health concern in Ethiopia. J Nutr Food Sci 6(4): $1-11$.

10. Silva KC, Assis CR, Oliveira VM, Carvalho LB Jr, Bezerra RS (2013) Kinetic and physicochemical properties of brain acetylcholinesterase from the peacock bass (Cichla ocellaris) and in vitro effect of pesticides and metal ions. Aquat Toxicol 126: 191-197.

11. Niessen W, Manini P, Andreoli R (2006) Matrix effects in quantitative pesticide analysis using liquid chromatography-mass spectrometry. Mass Spectrom Rev 25(6): 881-899.

12. Hem L, Khay S, Choi J, Morgan E, Abd El-Aty A, et al. (2010) Determination of trichlorfon pesticide residues in milk via gas chromatography with $\mu$-electron capture detection and GC-MS. Toxicol Res 26(2): 149-155.

13. Akhtar S, Ahad K (2017) Pesticides residue in milk and milk products: Mini review. Pak J Anal Environ Chem 18(1): 37-45.

14. Xu F, Ren K, Yang Y, Guo J, Ma G, et al. (2015) Immunoassay of chemical contaminants in milk: A review. J Integr Agric 14(11): 2282-2295.

15. Bhadekar R, Pote S, Tale V, Nirichan B (2011) Developments in analytical methods for detection of pesticides in environmental samples. Am J Analyt Chem 2(8A): 1-15.

16. Lee JK, Ahn KC, Stoutamire DW, Gee SJ, Hammock BD (2003) Development of an enzyme-linked immunosorbent assay for the detection of the organophosphorus insecticide acephate. J Agric Food Chem 51(13): 3695-3703.

17. Liu Y, Lou Y, Xu D, Qian G, Zhang Q et al. (2009) Production and characterization of monoclonal antibody for class-specific determination of 0 , 0-dimethyl organophosphorus pesticides and effect of heterologous coating antigens on immunoassay sensitivity. Microchem J 93(1): 36-42.

18. Xu ZL, Xie GM, Li YX, Wang BF, Beier RC, et al. (2009) Production and characterization of a broad-specificity polyclonal antibody for 0 , O-diethyl organophosphorus pesticides and a quantitative structureactivity relationship study of antibody recognition. Anal Chim Acta 647(1): 90-96.

19. Zhao F, Hu C, Wang H, Zhao L, Yang Z (2015) Development of a MAbbased immunoassay for the simultaneous determination of 0 , O-diethyl and 0, 0-dimethyl organophosphorus pesticides in vegetable and fruit samples pretreated with QuEChERS. Anal Bioanal Chem 407(30): 8959-8970.

20. Li X, Zhang H, Ji Y, Zheng Z, Bian Q et al. (2015) Immunochemical and molecular characteristics of monoclonal antibodies against organophosphorus pesticides and effect of hapten structures on immunoassay selectivity. Food Agric Immunol 216(1): 109-119.

21. Ferguson BS, Larkin KA (1994) Monitoring Parathion and Parathionmethyl in Ground, Surface and Rice Paddy Water with a Rapid and Sensitive Immunoassay. Book of Abstracts. Eighth IUPAC International Congress of Pesticide Chemistry. Washington, USA.

22. Wong J, Li Q, Hammock B, Seiber J (1991) Method for the analysis of 4-nitrophenol and parathion in soil using supercritical fluid extraction and immunoassay. J Agric Food Chem 39(10): 1802-1807.

23. Brimfield A, Lenz D, Graham C, Hunter K Jr (1985) Mouse monoclonal antibodies against paraoxon: potential reagents for immunoassay with constant immunochemical characteristics. J Agric Food Chem 33(6): 1237-1242. 
24. Heldman E, Balan A, Horowitz O, Ben-Zion S, Torten M (1985) A novel immunoassay with direct relevance to protection against organophosphate poisoning. FEBS Lett 180(2): 243-248.

25. Hunter KW Jr, Lenz DE (1982) Detection and quantification of the organophosphate insecticide paraoxon by competitive inhibition enzyme immunoassay. Life Sci 30(4): 355-361.

26. Yaneva M, Ivanov Y, Godjevargova T (2017) Preparation of polyclonal antibodies with application for an organophosphorus pesticide immunoassay. Anal Lett 50(8): 1-18.

27. Sajid M, Kawde AN, Daud M (2015) Designs, formats and applications of lateral flow assay: A literature review. J Saudi Chem Soc 19(6): 689705 .

28. Anfossi L, Di Nardo F, Cavalera S, Giovannoli C, Baggiani C (2018) Multiplex lateral flow immunoassay: An overview of strategies towards high-throughput point-of-need testing. Biosensors (Basel) 9: 1.

29. Kim YA, Lee EH, Kim KO, Lee YT, Hammock BD, Lee HS (2011) Competitive immunochromatographic assay for the detection of the organophosphorus pesticide chlorpyrifos. Anal Chim Acta 693(1-2): 106-113.

30. Zhang C, Zhang Y, Wang S (2006) Development of multianalyte flowthrough and lateral-flow assays using gold particles and horseradish peroxidase as tracers for the rapid determination of carbaryl and endosulfan in agricultural products. J Agric Food Chem 54(7): 25022507.

31. Hua X, Yang J, Wang L, Fang Q, Zhang G, Liu F (2012) Development of an enzyme linked immunosorbent assay and an immunochromatographic assay for detection of organophosphorus pesticides in different agricultural products. Plosone 7(12): e53099.

32. Liu C, Jia Q Yang C, Qiao R, Jing L, et al. (2011) Lateral flow immunochromatographic assay for sensitive pesticide detection by using Fe304 nanoparticle aggregates as color reagents. Anal Chem 83(17): 6778-6784.

33. Wu S, Duan N, Gu H, Hao L, Ye H, et al. (2016) A review of the methods for detection of Staphylococcus aureus enterotoxins. Toxins (Basel) $8(7): 176$

34. Kolosova AY, Park JH, Eremin SA, Kang SJ, Chung DH (2003) Fluorescence polarization immunoassay based on a monoclonal antibody for the detection of the organophosphorus pesticide parathion-methyl. J Agric Food Chem 51(5): 1107-1114.

35. Xu ZL, Wang Q, Lei HT, Eremin SA, Shen YD, Wang H, et al. (2011) A simple, rapid and high-throughput fluorescence polarization immunoassay for simultaneous detection of organophosphorus pesticides in vegetable and environmental water samples. Anal Chim Acta 708(1-2): 123-129.

36. Welch NG, Scoble JA, Muir BW, Pigram PJ (2017) Orientation and characterization of immobilized antibodies for improved immunoassays (Review). Biointerphases 12(2): 02 D301.

\section{This work is licensed under Creative}

Commons Attribution 4.0 License

DOI: $10.19080 / J D V S .2019 .11 .555812$
37. El-Ansary A, Faddah L (2010) Nanoparticles as biochemical sensors. Nanotechnol Sci Appl 3: 65-76.

38. Godjevargova T, Ivanov Y, Dinev D (2017) Multiplex fluorescent immunoassay device based on magnetic nanoparticles. AIP Conf Proc $1809(1)$.

39. Font H, Adrian J, Galve R, Estévez MC, Castellari M, Gratacós-Cubarsí M, et al. (2008) Immunochemical assays for direct sulfonamide antibiotic detection in milk and hair samples using antibody derivatized magnetic nanoparticles. J Agric Food Chem 56(3): 736-743.

40. Atanasova M, Vasileva N, Godjevargova T (2017) Determination of aflatoxin M1 in milk by a magnetic nanoparticle-based fluorescent immunoassay. Anal Lett 50(3): 452-469.

41. Becheva Z, Ivanov Y, Gabrovska K, Godjevargova T (2019) Rapid immunofluorescence assay for staphylococcal enterotoxin A using magnetic nanoparticles. Int J Food Sci Technol 54(3): 916-922.

42. Yaneva M, Ivanov Y, Todorov N, Godjevargova T (2018) Magneticnanoparticles-based fluorescent immunoassay for individual and simultaneous determination of dichlorvos and paraoxon in milk. Food Agric Immunol 29(1): 228-243.

43. Ivanov Y, Yaneva M, Godjevargova T, Zvereva E (2019) Immunofluorescence assay of pesticides on the base of immobilized multi-polyclonal antibody. Food Sci Appl Biotechnol 2(1): 46-53.

44. Hu Y, Shen G, Zhu H, Jiang G (2010) A class-specific enzyme-linked immunosorbent assay based on magnetic particles for multiresidue organophosphorus pesticides. J Agric Food Chem 58(5): 2801-2806.

45. Li YF, Sun YM, Beier R, Lei HT, Gee S, et al. (2017) Immunochemical techniques for multianalyte analysis of chemical residues in food and the environment: A review. TrAc-Trend Anal Chem 88: 25-40.

46. Wang ST, Gui WJ, Guo YR, Zhu GN (2007) Preparation of a multi-hapten antigen and broad specificity polyclonal antibodies for a multiple pesticide immunoassay. Anal Chim Acta 587(2): 287-292.

47. Liang Y, Liu XJ, Liu Y, Yu XY, Fan MT (2008) Synthesis of three haptens for the class-specific immunoassay of 0,0-dimethyl organophosphorus pesticides and effect of hapten heterology on immunoassay sensitivity. Anal Chim Acta 615(2): 174-183.

48. Liang Y, Liu Y, Zhu JF, Fan MT, Liu XJ (2008) Production of broad specificity anti-methoxyorganophosphorus pesticides antibody. Chinese J Anal Chem 36(5): 647-652.

49. Shi H, Li H, Hua X, Zheng Z, Zhu G, et al. (2014) Characterization of multihapten antigens on antibody sensitivity and specificity for parathion. Anal Lett 47(16): 2699-2707.

50. Zikos C, Evangelou A, Karachaliou CE, Gourma G, Blouchos P, et al. (2015) Commercially available chemicals as immunizing haptens for the development of a polyclonal antibody recognizing carbendazim and other benzimidazole-type fungicides. Chemosphere 119: S16-S20.

\begin{tabular}{l} 
Your next submission with Juniper Publishers \\
will reach you the below assets \\
- Quality Editorial service \\
- Swift Peer Review \\
- Reprints availability \\
- E-prints Service \\
- Manuscript Podcast for convenient understanding \\
- Global attainment for your research \\
- Manuscript accessibility in different formats \\
( Pdf, E-pub, Full Text, Audio) \\
- Unceasing customer service \\
Track the below URL for one-step submission \\
https://juniperpublishers.com/online-submission.php \\
\hline
\end{tabular}

